\title{
Adsorption of 2-picoline and 3-Amino-2-picoline onto Kaolin and Organo-modified Kaolin
}

\author{
SAEEDEH HASHEMIAN* and YALDAPARSAEI \\ Department of Chemistry, Islamic Azad University, Yazd Brunch, Yazd, Iran. \\ *Corresponding author E-mail: Sa_hashemian@yahoo.com \\ http://dx.doi.org/10.13005/ojc/310119
}

(Received: December 20, 2014; Accepted: January 24, 2015)

\begin{abstract}
The adsorption of 2-picoline (PC) and 3-Amino-2-picoline (APC) onto kaolin and organomodified kaolin was investigated. Tetraethylamoniumiodide (TEAI) was used as modification reagent. The sorbent was characterized by FTIR, XRD, SEM and BET methods. The influence of various parameters like contact time, $\mathrm{PH}$, adsorbent dose and initial concentration of $\mathrm{PC}$ and APC was studied. The adsorption kinetics, thermodynamic and isotherms were thoroughly examined. Results show that a pH value of more than 6 and contact time $60 \mathrm{~min}$ is favorable for adsorption. The dynamic data fit well with the pseudo- first-order kinetic model. Thermodynamic results revealed that the adsorption process is an endothermic and spontaneously process. The isothermal data could be well described by the Freundlich equation. The results indicate that kaolin/TEAl could be employed as low cost sorbent for removal of organic pollutant from water.
\end{abstract}

Key words: Adsorption, Kaolin, Organo-modified kaolin, 2-picoline, 3-Amino-2-picoline.

\section{INTRODUCTION}

Natural clay minerals are well known compounds. The kinds of clays are largely used in industrial products such as ceramic, paint, coatings, water purification and drilling mud $^{1-3}$. They are low cost, abundance in most continents of the word, high sorption properties and potential for ion exchange, therefore, clay materials are strong candidates as adsorbents ${ }^{4,5}$. In recent years, there has been an increasing interest in utilizing clay minerals such as bentonite ${ }^{6-7}$ and kaolin ${ }^{8,9}$ to adsorb organic and inorganic molecules. The adsorption properties of clays can be improved by surface modification ${ }^{10}$. The replacement of inorganic exchange cations with quaternary alkylammonium derivatives makes clays mineral organophilic, with a high affinity for the adsorption of pollutant compounds from aqueous solutions ${ }^{11,12}$. It was suggested that possible use of ammonium ions of the type $\mathrm{NH}_{3} \mathrm{R}^{+}, \mathrm{NH}_{2} \mathrm{R}_{2}, \mathrm{NHR}_{3}$ and $\mathrm{NR}_{4}^{+}$throw more light on the mechanism of cation exchange in lay minerals. The R of alkyl hydrocarbon, occupy the exchange sites of clay and hence the surface area is increased ${ }^{13}$. 
2-picoline is a derivative of pyridine. 2-picoline is considered to be a hazardous chemical. Various industrial units manufacturing pyridine and its derivatives, pharmaceutical units, etc. discharge 2picoline-bearing wastewaters ${ }^{14}$. Various physicchemical and biological treatment techniques are suggested for the treatment of 2-picoline-bearing wastewaters.Adsorptionis relatively useful and economical for removal of pyridine derivative ${ }^{15-17}$.

In this study, kaolin obtained from a local mine in IRAN (Yazd), was modified by tetra ethylamoniumiodide (TEAI). The 2-picoline (PC) and 3-Amino-2-picoline (APC) as models of pollutant adsorption properties were tested.

\section{EXPERIMENTAL}

\section{Materials and methods}

All the reagents used in the experiments were in analytical grade and were used without further purification. All the experiments were conducted at room temperature. The raw kaolin was obtained from local mine of Iran (tavansil. Co). Kaolin particle size fractions was180- $200 \mu \mathrm{m}$ and it was crushed and dried at $150^{\circ} \mathrm{C}$ in an oven for $5 \mathrm{~h}$ prior to use.

The 2-picoline (PC), 3-Amino-2-picoline (APC) and tetra ethylamoniumiodide (TEAI) were purchased from Merck. The standard solutions of $1000 \mathrm{mg} \mathrm{L}^{-1}$ of PC and APC were prepared as stock solutions and subsequently whenever necessary, diluted.

The preparation process was carried out by dispersing of $10 \mathrm{~g}$ kaolin to a $100 \mathrm{~mL}$ of TEAI 1

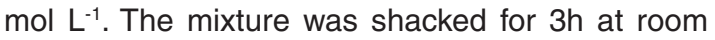
temperature. The kaolin loaded with TEAI was filtered, washed repeatedly with copious amounts of distilled water, then dried in air andamend kaolin/ TEAI (KT), stored for subsequent studies.

Adsorption studies were carried out in glass vessels with agitation provided by a shaker. The temperature was controlled at $25^{\circ} \mathrm{C}$ by air bath. The suspensions containing $0.1 \mathrm{~g}$ sorbent and varying amounts of $P C$ and $A P C$ were shaken on an orbital shaker at $150 \mathrm{rpm}$. For adsorption experiments, $50 \mathrm{~mL}$ PC and APC solution $(7.5 \mathrm{mg}$ $\mathrm{L}^{-1}$ ) and $0.1 \mathrm{~g}$ of KTsorbent were used. The effect of
$\mathrm{pH}$ was studied by adjusting the $\mathrm{pH}$ of the solutions in the range of 2-12 with $0.1 \mathrm{~N} \mathrm{NaOH}$ or $\mathrm{HCl}$ solutions. Samples for the kinetic study were taken at different time intervals. To evaluate the adsorption thermodynamic parameters, the effect of temperature on adsorption were carried out at 20$60{ }^{\circ} \mathrm{C}$. The amount of PC and APC adsorbed by sorbent was calculated by the following mass balance relationship:

$$
\% \text { Adsorption }=\left(\mathrm{C}_{0}-\mathrm{C}_{\mathrm{e}}\right) / \mathrm{C}_{0} \times 100
$$

Where, $\mathrm{C}_{0}$ and $\mathrm{C}_{\mathrm{e}}$ are the initial and equilibrium solution concentrations of PC and APC $\left(\mathrm{mg} \mathrm{L}^{-1}\right)$.

\section{Characterization method}

IR measurements were performed by FTIR tensor-27 of Burker Co., using the $\mathrm{KBr}$ pellet. UVVis spectrophotometer $160 \mathrm{~A}$ Shimadzu was used for determination of concentration of pyridine compounds contaminant. All pH measurements were carried out with an ISTEK- 720P pH meter. The specific BET surface area was measured at $77 \mathrm{~K}$ by (Quanta chrome, Autosorb-1). The elemental analysis performed by an elemental Costech- ECS4010 apparatus. The powder $X$-ray diffraction studies were made on Philips PW3719 X-ray diffractometer by using $\mathrm{Cu}-\mathrm{K}_{\alpha}$ radiation of wave length $1.54060 \AA$.

\section{RESULTS AND DISCUSSION}

\section{Characterization of KT sorbent}

The FIIR Spectrum is generally used to identify some of the characteristic functional groups capable of absorbing organic. For comparison the FTIR spectra of kaolin and Kt samples are included. In order to obtain complementary evidence for the intercalation of quaternary alkyl ammoniumcations into the silicate lattice, FTIR spectra were recorded in the region $400-4000 \mathrm{~cm}^{-1} \mathrm{Fig}$. 1. Show the FTIR of kaolin and kaolin/TEAI (KT).

Table 1: Elemental analysis of kaolin, TEAI and KT

\begin{tabular}{lccc}
\hline Samples & \%C & H\% & $\% \mathbf{N}$ \\
\hline K & $0(0)$ & 0.8 & 0 \\
TEAI & 38.2 & 7.9 & 5.4 \\
K-TEAI & 5.8 & 2.5 & 1.3 \\
\hline
\end{tabular}


The absorption band at $3600-3700 \mathrm{~cm}^{-1}$ is due to stretching vibrations of structural $\mathrm{OH}$ groups. The band at 1119 and $797 \mathrm{~cm}^{-1}$ are assignedto $\mathrm{Si}$ asymmetrical stretching. A pair of strong bands 2900 and $3004 \mathrm{~cm}^{-1}$ were observed only on the KT; they can be assigned to the symmetric and asymmetric stretching vibrations of methylen group $v_{\mathrm{CH} 2}[4]$. This band is not observed in kaolin.

The elemental analyses ofkaolin and KT are presented in Table 1. The content of $\mathrm{C}, \mathrm{H}$ and $\mathrm{N}$ in KT was increased by the modification of TEAI on the kaolin. In particular, the presence of carbon and nitrogen in the KT confirmthe presence of TEAI onto kaolin.

The XRD patterns of the kaolin and KT are shown in Fig. 2. XRD patterns indicated the presence of free quartz in kaolin. The kaolin and KT diffraction pattern show intense peak at $2 \theta$ angle of $26.6^{\circ}$ assigned to quartz $\left(\mathrm{Si}_{3} \mathrm{O}_{6}\right)$. The XRD patterns of $\mathrm{KT}$ shows reflections characteristic for both kaolin and $\mathrm{KT}$, but at lower intensity which clearly indicates the presence of TEAI, which has not been removed by washing. It is important the main phase of kaolin (quartz) has not any change after loading with TEAI. Results of XRF analysis are shown in Table 2.

BET results of $\mathrm{K}$ and $\mathrm{KT}$ are shown in Table 3. The specific surface area of $\mathrm{K}$ and $\mathrm{KT}$ was
7.78 and $9.58 \mathrm{~m}^{2} \mathrm{~g}^{-1}$ respectively. The surface area of kaolin increaseswith modification. The increase of the specific surface area indicated the innersurfaces and regions of the sorbentmay becomemore accessiblefor PC and APC. The increasing of surface area, is increased the sorption amount and increase the removal efficiency of PC and $\mathrm{APC}^{12}$.

\section{Effect of contact time}

The effect of contact time on removal of PC and APA onto kaolin and KT is shown in Fig. 3.The adsorption of PC and APA occurred very quickly from the beginning of the experiments. This may be indicative of chemical adsorption. Maximum adsorption of PC and APC onto KT was observed at $60 \mathrm{~min}(70 \%)$; it can be said that beyond this there is almost no further increase in the adsorption and it is thus fixed as the equilibrium time. For adsorption onto kaolin maximum adsorption of PC and APC was attained at $80 \mathrm{~min}$ (35\%). As can be seen from the figures, when the equilibrium time increased, the amount of adsorption was not dramatically increased.

\section{Effect of $\mathrm{pH}$}

The $\mathrm{pH}$ is the most important factor affecting the adsorption process. To study the influence of $\mathrm{pH}$ on the adsorption of kaolin and $\mathrm{KT}$, experiments were performed using various initial

Table 2: XRF analysis of kaolin and Modified Kaolin with TEAI

\begin{tabular}{llcc}
\hline Compound Name & Formula & Modified Kaolin & Kaolin \\
\hline Quartz & $\mathrm{SiO}_{2}$ & 35.7 & 31 \\
Pyrophyllite & $\mathrm{Al}_{2} \mathrm{Si}_{4} \mathrm{O}_{10}(\mathrm{OH})_{2}$ & 12.2 & 22 \\
Muscovite & $\mathrm{KAl}_{2} \mathrm{Si}_{4} \mathrm{AlO}_{10}(\mathrm{OH})_{2}$ & - & 20.5 \\
Clinochlore & $\mathrm{Mg}_{2} \mathrm{Al}(\mathrm{Si}, \mathrm{Al}), \mathrm{O} \bullet \bullet(\mathrm{OH})^{\wedge}$ & 10.3 & - \\
Kaolinite & $\mathrm{Al}_{2} \mathrm{Si}_{2} \mathrm{O}_{5}(\mathrm{OH})_{4}$ & 8.9 & 26.4 \\
Illite-2 & $\mathrm{KAl},(\mathrm{Sif} \mathrm{Al}) \mathrm{O} \bullet \cdot(\mathrm{OH})$, & 32.9 & - \\
\hline
\end{tabular}

Table 3: The BET results of Kaolin and modified Kaolin

\begin{tabular}{lcccc}
\hline Sample & $\begin{array}{c}\text { Sample } \\
\text { Wight(g) }\end{array}$ & $\begin{array}{c}\text { Mean Pore } \\
\text { Diameter(nm) }\end{array}$ & $\begin{array}{c}\text { Total Pore } \\
\text { Volume }\left(\mathbf{C m}^{\mathbf{3}} \mathbf{g}^{-\mathbf{1}}\right)\end{array}$ & $\begin{array}{c}\text { Area } \\
\left.{\mathbf{( \mathbf { m } ^ { 2 }}}^{\mathbf{2}} \mathbf{- 1}\right)\end{array}$ \\
\hline Kaolin & 0.1930 & 35.56 & 6.92 & 7.78 \\
Modified Kaolin & 0.2563 & 26.88 & 6.44 & 9.58 \\
\hline
\end{tabular}


pHs varying from 2- 12. The uptake of PC and APC increased with increasing $\mathrm{pH}$ from 2-6. (see Fig. 4). It was observed that the adsorption is highly dependent on the $\mathrm{pH}$ of the solution, which affects the surface charge of the adsorbent and degree of ionization and speciation of the adsorbate. The high adsorption capacity is due to the strong electrostatic interaction between the PC and APC and sorbents. This could be explained by the fact that at low $\mathrm{pH}$, more protons will be available to protonate the amine and $\mathrm{NH}$ groups of $\mathrm{PC}$ and $\mathrm{APC}$, reducing the number of binding sitesfor Adsorption; therefore the adsorption of PC and APC is governed by electrostatic interaction ${ }^{18}$.

\section{Effect of initial concentration of PC and APC and amount of sorbent}

The effect of initial concentration of $P C$ and APC is shown in Fig. $5 \mathrm{a}$. It is found that the PC and APC sorption increases with an increase in concentration to $8 \times 10^{-4} \mathrm{M}$. It is attributed to the increase in the mass transfer driving force on account of an increase in $\mathrm{C}_{0}[19]$. Fig. 5b. Show the results of effect of sorbent dose on the sorption process. The experiments carried out using $30 \mathrm{~mL}$ of PC and APC. Removal efficiency increased up to $70 \%$ at $0.1 \mathrm{~g} \mathrm{KT}$ and then, remained constant regardless of increasing in the adsorbent dose. Positive correlation between adsorbent dose and removal efficiency of PC and APC is related to increasing surface area of available exchangeable sites $^{8,20}$. At KT composite more than $0.1 \mathrm{~g}$, the incremental PC and APC removal is very small, because particle-particle interaction such as aggregation at higher mass of sorbent leads to a decrease in the availability of total surface area of the sorbent.

In order to predict adsorption kinetic models of PC and APCsolutions, pseudo-first order and pseudo-second-order kinetic models were applied to the data.

The results of the kinetics experiments of sorption at $25^{\circ} \mathrm{C}$ are shown in Fig. 6 .

Table 4: Thermodynamic parameters of PC and APC adsorption onto KT

\begin{tabular}{|c|c|c|c|c|c|}
\hline$\Delta \mathrm{S}^{0}\left(\mathrm{~J} \cdot \mathrm{mol}^{-1} \cdot \mathrm{k}^{-1}\right)$ & $\Delta \mathrm{H}^{0}(\mathrm{KJ} \mathrm{mol}-1)\left(\mathrm{J}^{\prime} \mathrm{mol}^{-1}\right)$ & $\Delta \mathrm{G}^{0}\left(\mathrm{KJ} \mathrm{mol}^{-1}\right)\left(\mathrm{KJ} \mathrm{mol}^{-1}\right.$ & $\mathrm{K}_{\mathrm{c}}$ & $\mathrm{T}(\mathrm{K})$ & \\
\hline \multirow[t]{6}{*}{27.61} & 4.06 & $-4.9 \times 10^{-2}$ & 1.02 & 298 & \\
\hline & & $-1.7 \times 10^{-1}$ & 1.07 & 303 & \\
\hline & & -1.05 & 1.25 & 313 & $\mathrm{PC}$ \\
\hline & & -1.09 & 1.5 & 323 & \\
\hline & & -1.73 & 1.87 & 333 & \\
\hline & & -2.61 & 2.5 & 343 & \\
\hline \multirow[t]{6}{*}{32.4} & 5.20 & -0.65 & 1.3 & 298 & \\
\hline & & -0.774 & 1.36 & 303 & APC \\
\hline & & -0.966 & 1.45 & 313 & \\
\hline & & -1.27 & 1.63 & 323 & \\
\hline & & -1.78 & 1.9 & 333 & \\
\hline & & -2.48 & 2.2 & 343 & \\
\hline
\end{tabular}

Table 5: Langmuir and Freundlich isotherm constants for adsorption of PC and APC onto KT

\begin{tabular}{|c|c|c|c|c|c|c|}
\hline \multirow{2}{*}{$\begin{array}{l}\text { Sorbent } \\
\text { (KT) }\end{array}$} & \multicolumn{3}{|c|}{ Langmuir model } & \multicolumn{3}{|c|}{ Freundlich model } \\
\hline & $\begin{array}{c}q_{m} \\
\left(\mathrm{mg} \mathrm{g}^{-1}\right)\end{array}$ & $\begin{array}{c}K_{I} \\
\left(L \mathrm{mg}^{-1}\right)\end{array}$ & $R^{2}$ & $\begin{array}{c}K_{F} \\
(\text { L/g) }\end{array}$ & $n$ & $R^{2}$ \\
\hline PC & 1.984 & 0.085 & 0.826 & 0.735 & 0.833 & 0.997 \\
\hline APC & 1.522 & 0.072 & 0.89 & 0.724 & 0.824 & 0.988 \\
\hline
\end{tabular}


The rates of $\mathrm{PC}$ and $\mathrm{APC}$ sorption were determined by testing pseudo-first order and pseudo-second-order kinetic models.

The pseudo-first order model assumes that the rate of change of solute uptake with time is directly proportional to difference in saturation concentration and amount of solid uptake with time ${ }^{21}$.

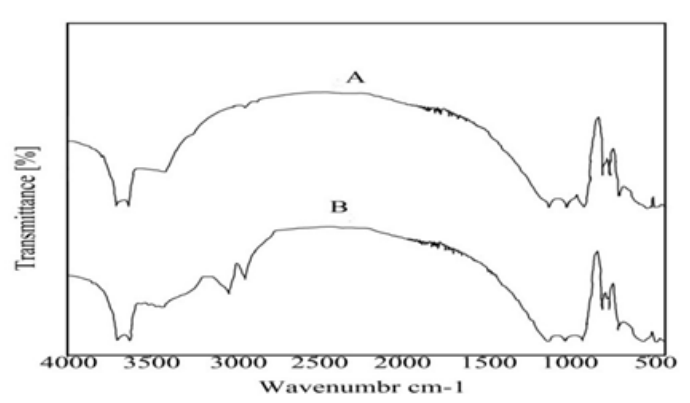

Fig. 1: FTIR spectra of a- Kaolin and b- Kaolin/TEAI

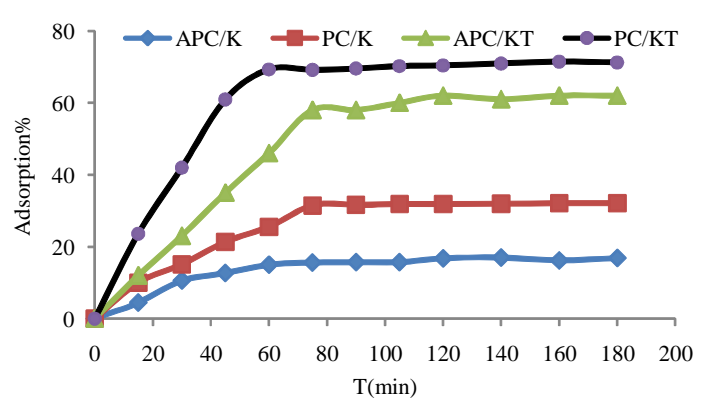

Fig. 3.Effect of contact time on the adsorption of PC and APA onto kaolin and KT

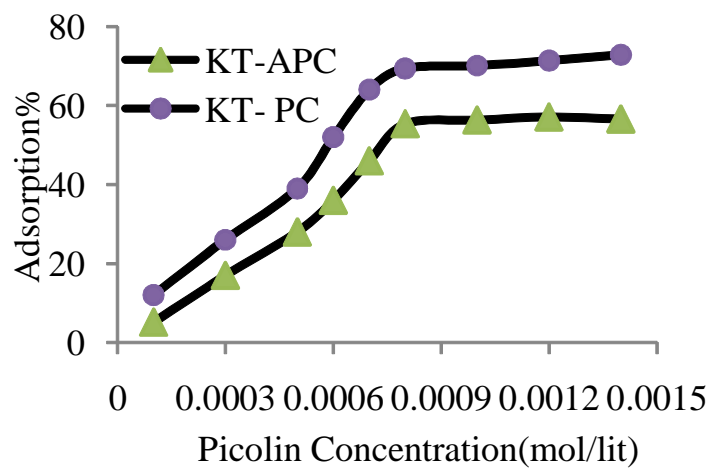

$$
\ln q_{t}=k_{1} t-\ln q_{e}
$$

Where $q_{e}$ and $q_{t}$ are the amounts of PC and APC adsorbed per unite mass of the adsorbent $\left(\mathrm{mg} \mathrm{g}^{-1}\right)$ at equilibrium and time $\mathrm{t}$, respectively and $\mathrm{k}_{1}$ is the rate constant of adsorption $\left(\mathrm{min}^{-1}\right)$. When $\mathrm{Inq}_{\mathrm{t}}$ was plotted against time, a straight line should be obtained with a slope of $k_{1}$, if the first order kinetics is valid.

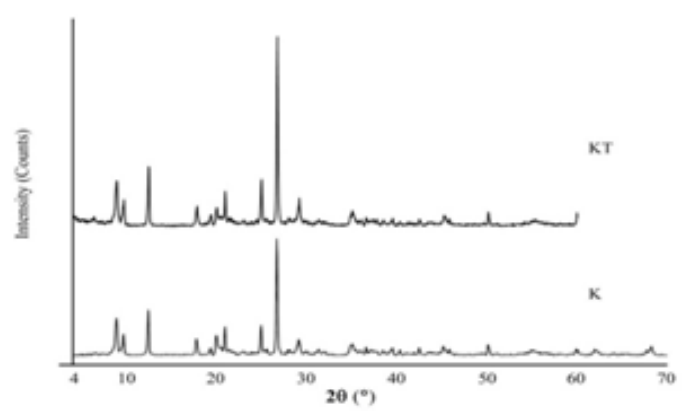

Fig. 2: XRD patterns of Kaolin and KT

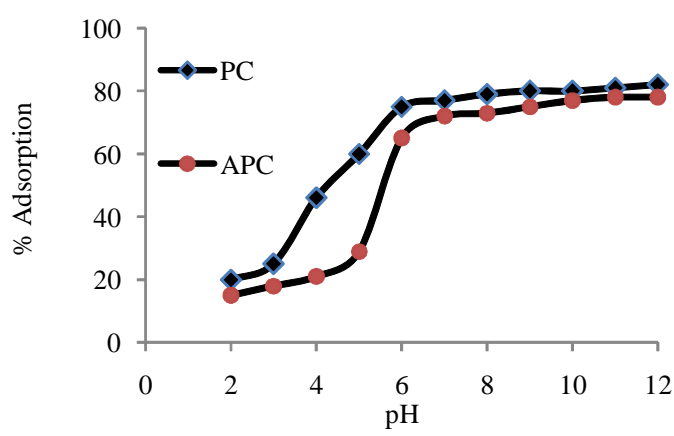

Fig. 4: Effect of $\mathrm{pH}$ on the adsorption of PC and APC onto KT

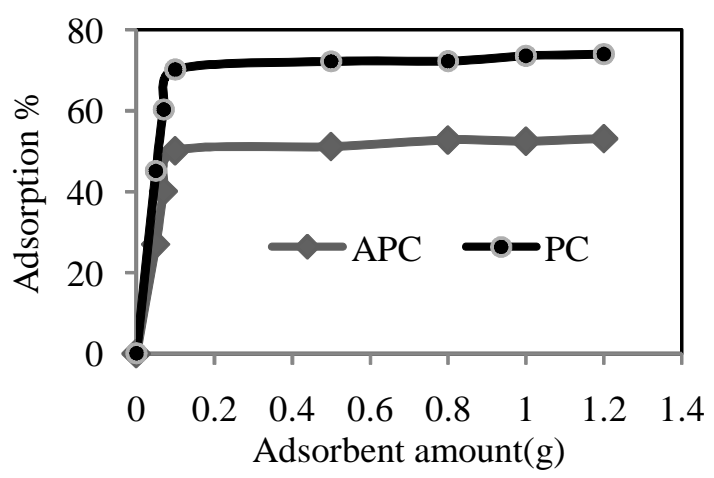

Fig. 5: Effect of a-initial concentration of PC and APC and b-amount of sorbent 
The pseudo-second order model as developed by Ho and McKay $^{22}$ has the following form:

$$
t / q_{t}=t / q_{e}+1 /\left(k_{2} q_{e}^{2}\right)
$$

Where $q_{e}$ and $q_{t}$ represent the amount of $\mathrm{PC}$ and APCadsorbed $\left(\mathrm{mg} \mathrm{g}^{-1}\right)$ at equilibrium and at any time. $\mathrm{k}_{2}$ in the rate constant of the pseudosecond order equation $\left(\mathrm{g} \mathrm{mg}^{-1} \mathrm{~min}^{-1}\right)$. A plot of $\mathrm{t} / \mathrm{q}$ versus time ( $t$ ) would yield a line with a slope of $1 / q_{e}$ and an intercept of $1 /\left(\mathrm{k}_{2} \mathrm{q}_{\mathrm{e}}{ }^{2}\right)$, if the second order model is a suitable expression. The kinetic model with a higher correlation coefficient $r^{2}$ was selected as the most suitable one.

It was found that application of pseudofirst order kinetics provides better correlation coefficient of experimental data than the pseudo second order model for adsorption of PC and APC onto KT composite. The good correlation coefficients were obtained by fitting the experimental data to Eq (1), indicating that the adsorption process of PC and APC onto KTis pseudo-first order. The rate constant of PC and APC are $2.04 \times 10^{-2}$ and $2.09 \times$ $10^{-2}$, respectively.

\section{Thermodynamic studies}

The thermodynamic parameters such as change in standard free energy $\left(\Delta G^{\circ}\right)$, enthalpy $\left(\Delta \mathrm{H}^{\circ}\right)$ and entropy $\left(\Delta S^{\circ}\right)$, were determined by using the following equations and are given in Table 4.

$$
\begin{aligned}
& \mathrm{K}_{\mathrm{C}}=\mathrm{C}_{\mathrm{A}} / \mathrm{C}_{\mathrm{S}} \\
& \Delta \mathrm{G}^{\circ}=-\mathrm{RT} \ln \mathrm{K}_{\mathrm{C}} \\
& \operatorname{Ln~K_{\mathrm {C}}}=\Delta S^{\circ} / \mathrm{R}-\Delta H^{\circ}
\end{aligned}
$$

Where, $\mathrm{K}_{\mathrm{C}}$ is the equilibrium constant, $\mathrm{C}_{\mathrm{A}}$. is the amount of PC and APC (mg) adsorbed on the adsorbent per $\mathrm{dm}^{3}$ of solution at equilibrium, and $\mathrm{C}_{\mathrm{S}}$ is the equilibrium concentration $\left(\mathrm{mg} \mathrm{dm}^{-3}\right)$ of $\mathrm{PC}$ and $\mathrm{APC}$ in the solution. $\mathrm{T}$ is the solution temperature (K) and $\mathrm{R}$ is the gas constant. $\Delta H^{\circ}$ and $\Delta S^{\circ}$ were
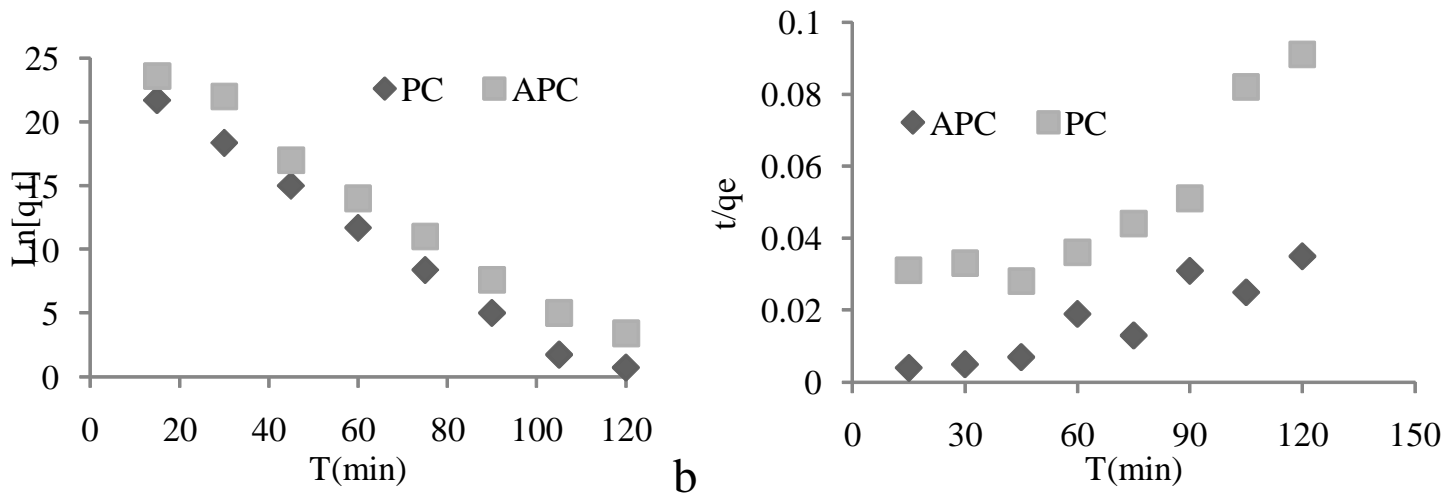

Fig. 6: (a) pseudo-first order and (b) Pseudo-second order kinetics for adsorption of IC on

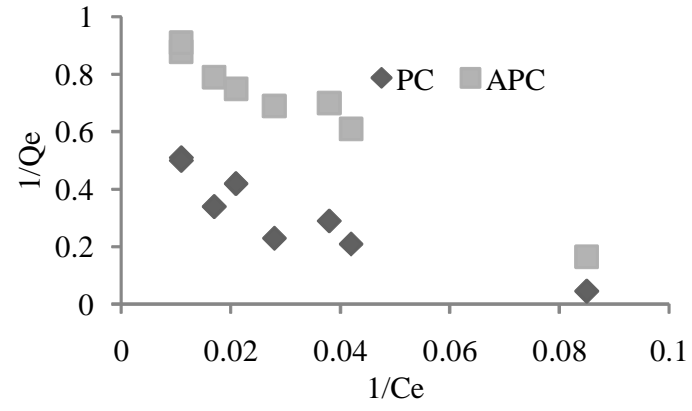

Fig. 7: Langmuir and Freundlich isothermplots for adsorption of PC and APC onto KT

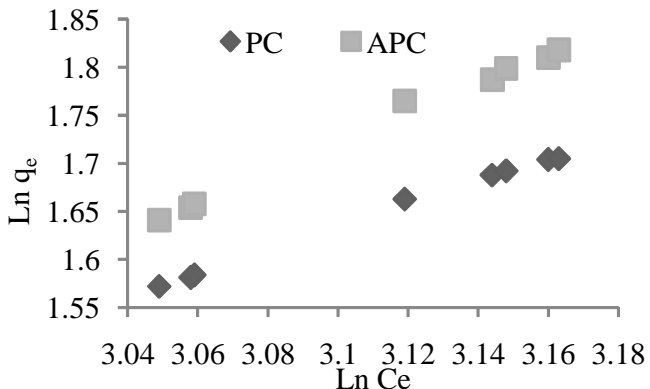

Fig. 8: Freundlich isotherm plot for adsorption of PC and APC onto KT 
calculated from the slope and intercept of van t Hoff plots of In KC vs $1 / \mathrm{T}$. The resultsare listed in Table 4. The results are shown, when the temperature increased from 25 to $70{ }^{\circ} \mathrm{C}, \Delta \mathrm{G}^{0}$ is decreased. It is indicating the adsorption was spontaneous and favorable at high temperatures.

The positive values of the standard enthalpy change $\left(\Delta H^{\circ}\right)$, which are 4.06 and 5.02 for PC and APC; indicate that the interaction of PC and APC molecules with clay is endothermic in nature. In addition, the standard enthalpy change is lower than $40 \mathrm{KJ} \mathrm{mol}^{-1}$, indicates that the adsorption is involving weak forces of attraction ${ }^{13}$.

\section{Adsorption isotherm studies}

Adsorption capacity and adsorption behavior of PC and APC on KT can be illustrated by adsorption isotherm. Data from the adsorption isotherms were modeled using the Langmuir and Freundlich isotherm models with the resulting isotherm constants presented in Table 5.

The Langmuir isotherm theory is based on the assumption of adsorption on a homogenous surface. The Langmuir equation can be written in the following form:

$$
q_{e}=q_{m} K_{L} C_{e} /\left(1+K_{L} C_{e}\right)
$$

The linearized form of Langmuir can be written as follows (Fig. 7):

$$
C_{e} / q_{e}=1 / q_{m} K_{L}+C_{e} / q_{m}
$$

Where $q_{e}$ is the solid phase equilibrium concentration $\left(\mathrm{mg} \mathrm{g}^{-1}\right) ; C_{e}$ is the liquid equilibrium concentration of PC and APC in solution (mg L-1); $K_{L}$ is the equili1ium constant related to the affinity of binding sites $\left(\mathrm{L} \mathrm{mg}^{-1}\right)$; and $\mathrm{q}_{\mathrm{m}}$ is the maximum amount of the sorbate per unite weight of adsorbent for complete monolayer coverage.

The Freundlich isotherm describes adsorption where the adsorbent has a heterogeneous surface with adsorption sites that have different energies of adsorption. The energy of adsorption is varies as a function of the surface coverage $\left(q_{e}\right)$ and is represented by Freundlich constant $K_{F}\left(L g^{-1}\right)$ in Eq. 8.

$$
q_{e}=K_{F} C_{e}^{m}
$$

Where $K_{F}$ is roughly an indicator of the adsorption capacity and $n$ is the heterogeneity factor which has a lower value for more heterogeneous surfaces.

In most references, Freundlich adsorption Equation (8) may also be expressed as Equation (9) (see Fig. 8):

$$
\ln q_{e}=\ln K_{F}+1 / n \ln C_{e}
$$

All the correlation coefficient, $\mathrm{R}^{2}$ value and the constants obtained for the models from Table 5 show that the Freundlich isotherm was suitable equation to describe the adsorption equilibrium of $\mathrm{PC}$ and $\mathrm{APC}$ onto KT.

\section{CONCLUSION}

The surface of raw kaolin is not more effective adsorbent for the removal of organic compounds from aqueous solution. However, kaolin may be modified with organic cations (TEAI) in a manner that significantly improves its capability of removing contaminants from water. The adsorption of PC and APC from aqueous solution using organo-kaolin was investigated. The results ofpresent investigation indicate thekaolin modified by TEAI has suitable adsorption capacity for removal of PC ad APC from aqueous solution. Kinetic data of adsorption were fitted by the pseudo-first-order kinetic model. Thermodynamic constants were also evaluated using equilibrium constants changing with temperature. The negative value of " $\mathrm{G}$ "indicated spontaneity and the positive values of " $\mathrm{H}^{0}$ showed the endothermic natureofadsorption, respectively. The Freundlich adsorption isotherm was found to have the best fit to the experimental data. 


\section{REFERENCES}

1. Darvishi,Z.;Morsali, A,;Colloids Surf. A: Physicochem. Eng. Aspects, 2011, 377,1519.

2. Zhang, D.; Zhou. C. H.;Appl. Clay Sci.2010, 50, 1-11.

3. Matuik, J.;Stodolak, E.; Bahranowaski, K.; Appl. Clay Sci.2011, 51, 102-109.

4. Atta, A.Y.;Jbril, B.Y.; Appl. Clay Sci.2012, 61, 8-13.

5. Resmi, G.; Thampi, S. G.;Chandrakaran, S.;Environ. Technol. 2012, 33 (1-3), 291-297.

6. Hashemian, S.;Main group Chem.2007, 6 (2), 97-107.

7. Hashemian, S.;African J. Biotechnol.2010, 9 (50), 8667-8671.

8. Hashemian, S.; Main Group Chem. 2011, 10, 105-114.

9. Hmdikaraoglu, M.; Dogan, M. D.;Alkan, M.;Desalination,2010, 256, 154-165.

10. Vidal, N.;Volzone, C.;Mater. Res.2012, 15 (6), 944-954.

11. Lee, S. M.;Tiwari, D.; Appl. Clay Sci.2012,5960, $84-102$.
12. Ma, J.; Zhu, L.;J. Hazard. Mater. B. 2006, 136, 982-988.

13. SafaOzcan, A.; Erdem, B.;Ozcan, A.;J. Colloid Inter. Sci. 2004, 280, 44-54.

14. Srivastava, V. C.;Mall, I.D.; Mishra, I. M.; J. Hazard. Mater.2006,134(1-3), 257-267.

15. Mohan, D.; Singh, K.P.;Ghosh, D.;Environ. Sci. Technol. 2005, 39 (13), 5076-5086.

16. Lataye, D. H.; Mishra, I. M.; Mall, I. D.; Chem. Chem. Eng. J.2008, 138, 35-46.

17. Hashemian, S.; Mirshamsi, M.; J. Indust. Eng. Chem.2012, 18,2010-2015.

18. Li, G. Y.;Jiag, Y. R,;Colloid and Surfaces A: Physicochem. Eng. Aspects.2008, 320, 1118.

19. Hashemian, S.; Foroghimoghadam, A.;Chem. Eng. J.2014, 235: 299-306.

20. Hashemian, S.;Salimi, M.;Chem. Eng. J.2012, 188, 57-63.

21. Lagergren, S.;Handlingar, 1898,24, 1-39.

22. Ho, Y.S.; McKay, G.; J. Chem. Eng, 1998, 70, 115-124. 